\title{
Gamifire - A Scalable, Platform-Independent Infrastructure for Meaningful Gamification of MOOCs
}

Citation for published version (APA):

Klemke, R., Antonaci, A., \& Limbu, B. H. (2019). Gamifire - A Scalable, Platform-Independent Infrastructure for Meaningful Gamification of MOOCs. In A. Liapis, G. N. Yannakakis, M. Gentile, \& M. Ninaus (Eds.), Games and Learning Alliance: 8th International Conference, GALA 2019, Athens, Greece, November 27-29, 2019, Proceedings (pp. 256-265). Springer. Lecture Notes in Computer Science Vol. 11899 https://doi.org/10.1007/978-3-030-34350-7_25

\section{DOI:}

10.1007/978-3-030-34350-7_25

Document status and date:

Published: 01/11/2019

Document Version:

Early version, also known as pre-print

Please check the document version of this publication:

- A submitted manuscript is the version of the article upon submission and before peer-review. There can be important differences between the submitted version and the official published version of record. People interested in the research are advised to contact the author for the final version of the publication, or visit the DOI to the publisher's website.

- The final author version and the galley proof are versions of the publication after peer review.

- The final published version features the final layout of the paper including the volume, issue and page numbers.

Link to publication

\section{General rights}

Copyright and moral rights for the publications made accessible in the public portal are retained by the authors and/or other copyright owners and it is a condition of accessing publications that users recognise and abide by the legal requirements associated with these rights.

- Users may download and print one copy of any publication from the public portal for the purpose of private study or research.

- You may not further distribute the material or use it for any profit-making activity or commercial gain

- You may freely distribute the URL identifying the publication in the public portal.

If the publication is distributed under the terms of Article 25fa of the Dutch Copyright Act, indicated by the "Taverne" license above, please follow below link for the End User Agreement:

https://www.ou.nl/taverne-agreement

Take down policy

If you believe that this document breaches copyright please contact us at:

pure-support@ou.nl

providing details and we will investigate your claim.

Downloaded from https://research.ou.nl/ on date: 26 Apr. 2023 


\title{
Gamifire - A scalable, platform-independent Infrastructure for Meaningful Gamification of MOOCs
}

\author{
Roland Klemke ${ }^{1,2}$, Alessandra Antonaci ${ }^{1}$, and Bibeg Limbu ${ }^{1}$ \\ 1 Welten Institute, Open University of the Netherlands \\ 2 Cologne Game Lab, TH Köln
}

\begin{abstract}
Gamification aims at addressing inherent problems of massive open online courses (MOOC): high dropouts, lack of engagement, isolation, lack of individualization. However, each MOOC platform offers different features and technical interfaces. Also, each platform collects different sets of data about user interaction, learning progress, or completion and success rates. This is an obstacle to the theoretically sound application of gamification in a vendor independent way and to the evaluation of the impact of gamification. We define our understanding of meaningful gamification, introduce requirements for platformindependent gamification, present the resulting Gamifire infrastructure, and describe application cases. We also point out planned development activities.
\end{abstract}

Keywords: Gamifire $\cdot$ Gamification $\cdot$ Architecture $\cdot$ Scalability $\cdot$ MOOC · Platform Independence · Infrastructure

\section{Introduction and Related Work}

MOOCs, announced to improve worldwide education [16], come with downsides like high-drop out rates [4] and low learner engagement [7]. Gamification was introduced to improve situations of motivational gaps: applying game elements to boring activities adds the fun [6]. Relying on mostly extrinsic motivational factors (such as points, badges, and leaderboards), gamification does not yet exploit the potential of motivation and passion for learning [10].

However, meaningful gamification, i.e. gamification that is thoughtfully integrated with the learning process, using a composition of game elements [5] supporting the desired effects according to selected theories, can be beneficial to learners [15]. Designing meaningful gamification is complex and implementing it into MOOC platforms is another obstacle: platforms differ in technology, functionality and extensibility [20].

We studied this situation and developed the GaDeP framework for the design of gamification $[2,1]$, which we will briefly describe below. In this article, we highlight the technical side by introducing backgrounds and related works, describing our design and development approach, listing requirements, resulting 
in a description of the system architecture and implementation. We describe planned fields of application and conclude on insights gathered.

A categorization of gamification requirements is reported in [13]. We derive different requirements, as their approach focuses on business applications rather than open distance education. A corresponding gamification architecture [12] provides basic elements for a gamification platform, likewise focused on business platforms, lacking the openness required for platform-independence. A gamification framework for K-6 education collects elements for educational purposes and derives motivational goals [19], without reporting technical aspects. Another gamification platform focuses on software development processes [11], where specific software development tasks and process elements are gamified. Building on the mentioned approaches, we add a sound methodology, platform independence, scalability, and a focus on online learning.

\section{Research Design, and Development Approach}

Applying gamification to MOOCs is complex and comprises a number of decisions to be taken from interdisciplinary perspectives, such as: game design, psychology, learning science, technology-enhanced learning, human-computer interaction, and software engineering [17]. Many gamification attempts fail due to the lack of a clear design methodology [18]. Therefore, we investigate the following research questions: (RQ1) Can we develop a platform-independent, scalable platform to support the meaningful gamification of MOOC? (RQ2) Can we resolve the conflict between platform-independence and the required platform integration for meaningful gamification? (RQ3) Can Gamifire support different MOOCs and their educational contexts? To answer RQ1-RQ3 and to base Gamifire on solid grounds, our approach comprises three main perspectives:

1. A design perspective, combining game design with problem-based selection of theories into an evaluation-based continuous improvement cycle.

2. A user-experience and usability perspective, taking the interplay of learning environment and gamification into account.

3. A software-engineering perspective, transforming outcomes of the other perspectives into implementable requirements and architectural specifications.

Gamification design frameworks have been discussed in [18]. In $[2,1]$ we outline the six steps of our gamification design process (GaDeP) in detail, covering the first two perspectives: (1) application scenario analysis to understand characteristics of the application context, (2) problem definition to analyse specific problems to be addressed by gamification, (3) theoretical framework to understand the background of how to address the problem, (4) game element selection to find appropriate game elements matching the theoretic framework, (5) design and implementation to realise the selected game elements, and (6) evaluation to measure the resulting effects and continuously improve the approach. This article takes the software-engineering perspective, covering steps (4-6) of GaDeP. 


\section{$3 \quad$ Requirements}

The requirements for Gamifire are based on the application field and the gamification framework GaDeP (see table 1). Our Field of application is online learning in MOOCs. This defines (non-functional) attributes of the user environment and technical constraints. The gamification methodology defines functional aspects. It requires game elements and user processes to be interwoven. This impacts the selection of game elements and the way the MOOC platform and the gamification platform are integrated. Based on game elements selected in [2] we reflect this from a software engineering standpoint.

Table 1: Non-functional Requirements related to the Field of Application (Nx) and Functional Requirements related to the Gamification Methodology (Fx)

No. Requirements Description Non-functional Requirements related to the Field of Application (Nx)

N1 Scalability. MOOCs are designed for high numbers of learners. The gamification platform has to serve this amount of learners without significant run-time impact. This comprises scalability in terms of computing power, data storage, and network traffic.

N2 Platform independence. As different MOOC platforms exist, a gamification engine should cover many of these. At the same time, the integration of gamification into the target platform needs to be seamless in order to deliver a continuous learner experience.

N3 Content integration. Many game elements only make sense in connection to the content. The gamification engine needs to allow for these connections by tracking learner progress and learner interaction.

N4 The User experience of learners interacting with the MOOC platform should be enhanced by the gamification engine.

N5 Extensibility. The platform should be easily extensible to additional use cases. This covers adding new game elements, adapting existing game elements, or adding other functionality.

N6 Stability. The platform should provide a stable and reliable service with minimal human intervention.

N7 Security. The platform needs to store user related data in a secure way.

N8 GDPR. The data storage needs to be GDPR compliant.

N9 Multi-user support. Online learning may lead to a feeling of isolation, even if numerous learners share the same platform. Thus, the platform needs to support collaborative or competitive multi-user game elements.

N10 Web front-end. MOOC platforms are commonly accessed via webbrowsers. The gamification platform needs to offer web front-ends.

N11 User Group Size. The gamification platform and the choice of game elements should not restrict the number of MOOC users.

N12 Seamless integration. The user interface (UI) of the gamification platform needs to integrate with the MOOC platform to appear as part of the MOOC UI without the user having to navigate between the systems. 
Requirements (cont. table 1)

No. Requirement Description

N13 Responsive UI. The design, layout, and interaction mechanisms used should adapt to various end-user devices. The UI elements added to the MOOC should support all platforms the MOOC platform supports. Functional Requirements related to the Gamification Methodology (Fx)

F1 Data collection. GaDeP requires an evaluation step to be performed. To measure effects in different experimental settings requires to collect data about learner interaction in a flexible but structured way.

F2 User management integration. MOOC users register with the MOOC platform. The gamification platform needs to gather user information to avoid double registrations to provide the personalized service to the user (e.g. displaying individual information in the HUD to the MOOC user).

F3 Choice of game elements. The platform shall support a variety of combinable game elements to provide meaningful, gameful interaction. In the context of MOOC, these should according to GaDeP comprise at least the ones listed in F4-F12

F4 Communication. The platform needs to support synchronous and asynchronous forms of communication.

F5 Stimulated planning helps users to plan activities and to follow that plan. It thus requires functionality for planning, plan-based feedback and communication.

F6 Clans (or Guilds, Teams) organize users into groups, which can receive group-related assignments for collaborative or competitive work. This requires support for the grouping phase and group-based concepts of content visibility and access.

F7 Collaboration and Cooperation. Group members should be able to work together on some tasks.

F8 For Group competition, groups need some form of group-privacy to hide working progress from other groups.

F9 Individual and group challenges are assignments to be solved according to constraints (e.g. time limits, number of attempts, competition/collaboration modes). Challenges shall motivate users and are (usually) not part of the formal learning success calculation but count for users' engagement and may contribute to perceived social presence and sense of community.

F10 A Narrative presents learning content with a story line, that connects learning episodes and contextualizes learning content with this story. The gamification platform should allow to include narrative elements.

F11 In games Head-up displays (HUDs) show contextual information to the player. The gamification platform should include HUDs for relevant information in a non-intrusive way, to support the learning process and not interfering with it.

F12 Avatars. Users should be able to personalize their appearance in the game, by using an avatar representation. 


\section{Gamifire}

This section describes the design decisions leading to the architecture and implementation of Gamifire based on the requirements. It also reports on trade-offs and limitations.

To have many of the listed requirements covered on platform-level, Gamifire is implemented on top of the Google App Engine (GAE) cloud platform using a three-tier architecture, with database back-end (cloud data-store), application server, and front-end user-interface (UI) widgets. Choosing GAE enables us to meet the following requirements immediately:

- Scalability (N1) and Stability (N6) are core principles of GAE.

- Extensibility (N5) Gamifire is distributed as an open source solution ${ }^{3}$.

- Security (N7) and GDPR compliance (N8) are inherent aspects of GAE.

- Support for web front-ends (N10) is supported within GAE.

- GAE's native session management delivers multi-user support (N9).

- For Data collection (F1) Gamifire stores interaction information in the backend data-store and supports treatment/control groups.

Covering (F1), the back-end stores log information about user interactions, timestamps, and progress related data. The application server handles user related sessions, tracks user interactions, manages logging operations and generates feedback and UI-related content.

With platform-independence (N2) in mind, Gamifire uses user interface widgets to integrate into the MOOC platform through front-end integration. No back-end integration has to be performed (integrating data models, server interaction, session management or other back-end services). However, each game element/widget can store widget specific data. From the MOOC platform, Gamifire gathers the user, who is currently logged in and synchronizes Gamifire's user data with the MOOC at hand. In combination with the multi-user support and the scalability, this allows to support the same user group size (N11) as the MOOC platform itself.

To generate the UI in line with the front-end integration approach, Gamifire comprises a library of game element widgets, which provide the individualized views with respect to the user status. These widgets are embedded into the MOOC platform by adding them to the web-based front-end of the MOOC platform as HTML components. Through JavaScript introspection, they gather user information from the MOOC platform to synchronize user sessions and data between MOOC and Gamifire. Fig. 1 shows the Gamifire component architecture and its integration into a MOOC platform. Fig. 2 shows selected UI components displaying different game elements and components.

Content integration (N3) is in conflict with platform-independence. In section Trade-offs and limitations we discuss this situation. To keep the user experience (N4) close to the MOOC environment, we use style-sheets in Gamifire's frontend to adapt look and feel to the MOOC environment. This also supports the

\footnotetext{
${ }^{3}$ A public distribution of Gamifire is currently under preparation
} 
Fig. 1: Architecture of the Gamifire platform

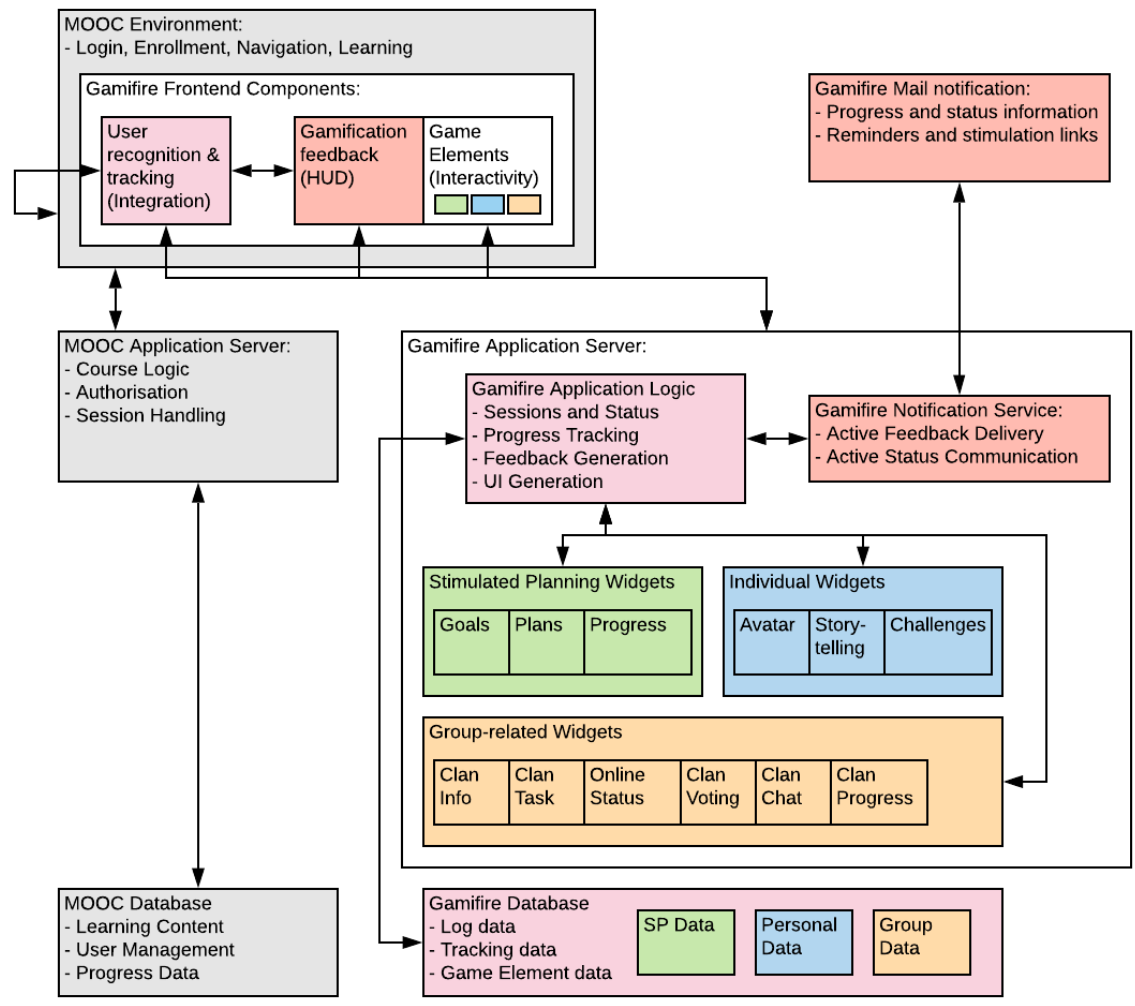

creation of responsive UI components (N13). In combination with the front-end integration, this also supports seamless integration into the MOOC platform (N12), where an important aspect of the front-end integration is the recognition of the user logged into the MOOC platform, which supports user management integration (F2)

Gamifire supports a number of game elements, as represented by the game element front-end components and the game element widget library: stimulated planning widgets, individual game element widgets, and group-related widgets. With this collection of game elements, requirements F4-F12 are covered: stimulated planning is directly supported with a set of specific widgets and frontend components (F5), the set of group-related widgets and components support communication channels (F4), clans (F6), collaboration via clan tasks and clan voting $(F 7)$, competition via online status and clan progress $(F 8)$, individual and group challenges (F9) are supported via challenges (individual) as well as clan tasks (group). Narrative is supported with specific information components as individual game element (F10). The HUD (F11) combines the Gamifire applica- 


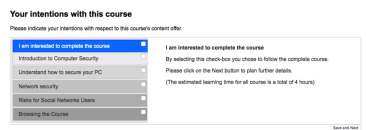

(a) SP: Intentions

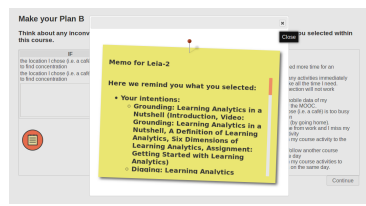

(d) SP: Memo

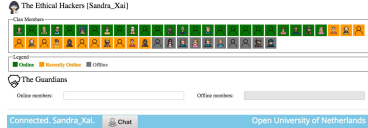

(g) HUD: Online status

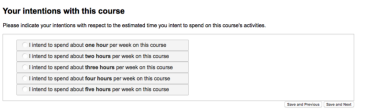

(b) SP: Intentions

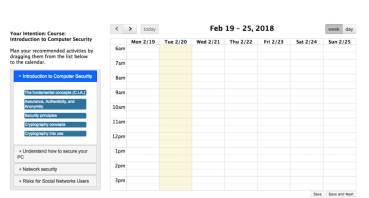

(e) SP: Planning

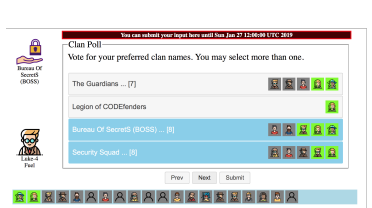

(h) Clan voting

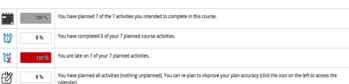

(c) HUD: Feedback

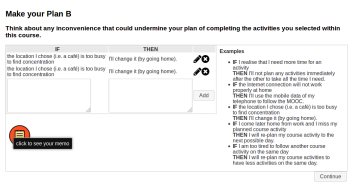

(f) SP: Plan B

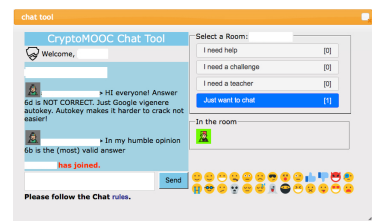

(i) Clan chat

Fig. 2: Screen-shots of Gamifire UI components.

tion logic with the gamification feedback front-end. The user avatar component implements the game element avatars (F12). The avatar is used to personalize the feedback component and online status, clan voting, clan chat, clan tasks and clan progress. With this coverage of game elements in Gamifire, also requirement F3 (choice of game elements) is covered. However, we do not claim completeness: additional game elements are planned to be added to Gamifire for a broader support of application cases and gamification scenarios.

Trade-offs and limitations. The most striking trade-off we have been facing during the development of Gamifire is between the platform-independence (N1) and the concept of meaningful gamification (F3-F12) combined with the functional-requirement for seamless integration (N12): while the former requires us to rely on shallow integration of Gamifire and the MOOC environment by means of front-end integration, the latter requires some understanding of the learning content and the corresponding learner progress within Gamifire. We addressed this trade-off with the following concept: when preparing a gamified MOOC, Gamifire is configured with a mirrored content structure (only the outline, not the contents itself), assigning content ids to recognizable page URIs. Through the tracking feature of the front-end integration, Gamifire can thus keep track of learner interactions within the MOOC and calculate interaction rates, learning progress, completion rates, etc. on its own data without having to query the MOOC platform's back-end. While this solution allows to keep the technical integration independent, it requires some extra effort to mirror 
the content structure into Gamifire. Especially, when a MOOC undergoes many changes, this may represent a bottleneck and a source of possible mistakes.

While this article mainly focuses on technical aspects, conflicts may also arise in the combination of game elements: narrative e.g. is in conflict with stimulated planning. A narrative connects learning contents into episodes of a story, stimulated planning allows users to plan individual learning activities, which requires a degree of independence. Gamifire does not automatically detect such conflicts and it is in the responsibility of the design team to make sure that the game elements used are not in conflict with each other.

The shallow integration according to the required platform-independence leads to another conflict in relation to narratives: narratives can be seen as part of the MOOC content but also expected to be part of the gamification design. For now, Gamifire does not resolve this conflict with a technical solution but leaves it to the course and gamification design team to resolve, where to apply which elements of a narrative: at this point learning design and gamification design need to be performed as a team-work.

\section{Application Cases and Results}

Even though the architecture and implementation of Gamifire meet the requirements set out in section 3, a proof of the applicability of the solution can only be achieved by applying it to a variety of cases. Gamifire has been applied to three different application cases, where different game elements have been selected and implemented due to a different focus of the application case:

(1) In a MOOC on information security, we explored the impact of planning behaviour on goal achievement by implementing the game element "stimulated planning" according to the implementation intention theory [8]. Participants had to state their goals, plan their activities (including a coping plan for inconveniences), received plan related feedback, and were stimulated to re-plan, when the plan was not met. We applied the first version of Gamifire to Moodle first and to Open EdX later. This platform switch confirmed the platform-independence of Gamifire, by restricting the number of modifications necessary mainly to the front-end integration scripts. This version of Gamifire also underwent a usability study [1], which informed the further development of Gamifire.

(2) A MOOC on cryptography aimed at fostering engagement through perceived social presence and the development of a sense of community [9]. We implemented several game elements (clans, avatars, group activities, communication channels, online status) according to concepts described in [14]. Group awareness and team interactions were at the focus of this version, requiring fast updates and exchange of status information, activities, and communication, to allow Gamifire to keep group members informed about other group members' activities and states in close to real-time. This focus required us to balance server communication load, caching mechanisms, and load balancing mechanisms to allow fast communication without increasing server load too much [3]. 
(3) A MOOC on trusted learning analytics has been chosen for an updated version of the stimulated planning game element, which included an improved user interface, enhanced browser compliance, and updated feedback mechanisms.

To test Gamifire as data collection tool, we applied it to a MOOC on marine pollution without implementing specific game elements and collected student interactivity data for an A-B-Test designed within the features of the MOOC. The data collected here currently being analyzed.

\section{Conclusions and Future Work}

With the implementation of Gamifire, we were able to show that it is possible to deliver a "scalable, platform-independent, cloud-based Infrastructure for meaningful gamification of MOOC". We were able to meet the requirements collected for such a platform and to apply and test Gamifire in several application cases.

However, as we have seen from our application cases, the implementation and application of Gamifire faces a number of trade-offs, which show, that some conceptual issues have to be addressed in future work: (1) The solution found addressing the trade-off between platform-independence and meaningful gamification as highlighted in section 4 requires to be re-thought, in order to get rid of erroneous extra work. (2) The conflicts found between some of the game elements requires us to offer more guidance to designers of MOOCs and gamification in order to share a more clear understanding of which game elements combine well for which gamification goals. To achieve this, more research on the effects of specific game element configurations needs to be performed.

Gamification remains a process requiring well-defined procedures and concepts. We hope, that Gamifire based on the methodology presented contributes to a better understanding and application of meaningful gamification in online learning.

Acknowledgements. We thank teachers and participants for their support. Studies reported are approved by the university's ethical committee (cETO).

\section{References}

1. Antonaci, A., Klemke, R., Dirkx, K., Specht, M.: May the Plan be with you! A Usability Study of the Stimulated Planning Game Element Embedded in a MOOC Platform. International Journal of Serious Games 6(1) (2019)

2. Antonaci, A., Klemke, R., Kreijns, K., Specht, M.: Get Gamification of MOOC right! How to Embed the Individual and Social Aspects of MOOCs in Gamification Design. International Journal of Serious Games 5(3) (2018)

3. Antonaci, A., Klemke, R., Lataster, J., Kreijns, K., Specht, M.: Gamification of moocs adopting social presence and sense of community to increase user's engagement: An experimental study. In: Scheffel, M., Broisin, J., Pammer-Schindler, V., Ioannou, A., Schneider, J. (eds.) Transforming Learning with Meaningful Technologies. pp. 172-186. Springer International Publishing, Cham (2019) 
4. Atiaja, L., Proenza, R.: The MOOCs: origin, characterization, principal problems and challenges in Higher Education. Journal of e-Learning and Knowledge Society 12(1) (2016)

5. Björk, S., Holopainen, J.: Patterns in Game Design (Game Development Series), vol. 54. Charles River Media, 1 edn. (2004)

6. Deterding, S.: Gamification: designing for motivation. Interactions 19(4), 14-17 (2012)

7. Dillon, J., Bosch, N., Chetlur, M., Wanigasekara, N., Ambrose, G., Sengupta, B., D'Mello, S.: Student Emotion, Co-Occurrence, and Dropout in a MOOC Context. Educational Data Mining (2016)

8. Gollwitzer, P.M., Sheeran, P.: Implementation intentions and goal achievement: A metaanalysis of effects and processes. Advances in Experimental Social Psychology 38, 69-119 (2006). https://doi.org/10.1016/S0065-2601(06)38002-1

9. Gunawardena, C.N., Zittle, F.J.: Social presence as a predictor of satisfaction within a computermediated conferencing environment. American Journal of Distance Education 11(3), 8-26 (1997). https://doi.org/10.1080/08923649709526970

10. Hamari, J., Koivisto, J., Sarsa, H.: Does Gamification Work?-A Literature Review of Empirical Studies on Gamification. HICSS 14, 3025-3034 (2014)

11. Herranz, E., Colomo-Palacios, R., de Amescua Seco, A.: Gamiware: A Gamification Platform for Software Process Improvement. In: Eur. Conf. on Software Process Improvement. pp. 127-139 (2015). https://doi.org/10.1007/978-3-319-24647-5_11

12. Herzig, P., Ameling, M., Schill, A.: A Generic Platform for Enterprise Gamification. In: Joint Working Conference on Software Architecture \& 6th European Conference on Software Architecture (2012). https://doi.org/10.1109/WICSA-ECSA.212.33

13. Herzig, P., Ameling, M., Wolf, B., Schill, A.: Implementing Gamification: Requirements and Gamification Platforms. In: Gamification in Education and Business, pp. 431-450. Springer International Publishing, Cham (2015)

14. Luo, N., Zhang, M., Qi, D.: Effects of different interactions on students sense of community in e-learning environment. Computers and Education 115, 153-160 (2017). https://doi.org/10.1016/j.compedu.2017.08.006

15. de Marcos, L., Garcia-Lopez, E., Garcia-Cabot, A.: On the effectiveness of gamelike and social approaches in learning: Comparing educational gaming, gamification \& social networking. Computers \& Education 95, 99-113 (2016)

16. McAuley, A., Stewart, B., Siemens, G., Cormier, D.: The MOOC model for digital practice (2010)

17. Meschede, C., Knautz, K.: Gamification and Interdisciplinarity: Challenges in the Modern Knowledge Society. International Journal of Information Communication Technologies and Human Development 9(3), 1-13 (2017)

18. Mora, A., Riera, D., Gonzalez, C., Arnedo-Moreno, J.: A Literature Review of Gamification Design Frameworks. In: VS-Games 2015 - 7th International Conference on Games and Virtual Worlds for Serious Applications. IEEE (2015)

19. Simões, J., Redondo, R., Vilas, A.: A social gamification framework for a K-6 learning platform. Computers in Human Behavior 29(2), 345-353 (2013)

20. Taneja, S., Goel, A.: MOOC providers and their strategies. International Journal of Computer Science and Mobile Computing 3(5), 222-228 (2014) 